\title{
Incidence and Mortality of Dementia-Related Missing and Their Associated Factors: An Ecological Study in Japan
}

\author{
Shunsuke Murata, Misa Takegami, Daisuke Onozuka, Yuriko Nakaoku, \\ Akihito Hagihara, and Kunihiro Nishimura \\ Department of Preventive Medicine and Epidemiology, National Cerebral and Cardiovascular Center Research Institute, Osaka, Japan
}

Received March 27, 2020; accepted June 10, 2020; released online June 27, 2020

\begin{abstract}
Background: Dementia-related missing and subsequent deaths are becoming serious problems with increases in people with dementia. However, there are no sufficient studies investigating the incidence rate, the mortality rate, and their risk factors.

Methods: An ecological study aggregated at the Japanese prefectural level was conducted. Dementia-related missing persons cases and deaths in 2018 were extracted from the statistics of the National Police Agency in Japan. We extracted variables about older adults' characteristics, care, and safety as candidate variables considered to be relevant to dementia-related missing persons cases and deaths. Associations of the candidate variables with the incidence and mortality rates were analyzed using the generalized linear model (family: quasi-poisson, link: log) adjusted for confounding factors (proportion of older adults and gross prefectural product).

Results: The incidence rate and mortality rate per 100,000 person-year was 21.72 and 0.652 in Japan, respectively. One facility increase in the number of nursing care facilities for older adults per 100,000 persons aged 65-years-old or more was associated with a $7.9 \%$ (95\% confidence interval $[\mathrm{CI}], 3.3-12.4 \%)$ decrease in the incidence rate. One increase in the number of public health nurses per 100,000 persons was associated with a 3.2\% (95\% CI, 1.6-4.9\%) decrease in the incidence rate. A ten percent increase in the proportion of people who live in an urban area was associated with a $20.3 \%$ (95\% CI, 8.7-33.2\%) increase in the incidence rate and a $12.9 \%$ (95\% CI, 5.6-19.8\%) decrease in the mortality rate.

Conclusions: Identified associated factors may be useful for managing or predicting dementia-related missing persons cases and associated deaths.
\end{abstract}

Key words: dementia-related missing incident; death after dementia-related missing; dementia; ecological study

Copyright $\odot 2020$ Shunsuke Murata et al. This is an open access article distributed under the terms of Creative Commons Attribution License, which permits unrestricted use, distribution, and reproduction in any medium, provided the original author and source are credited.

\section{INTRODUCTION}

The prevalence of Alzheimer's disease has increased rapidly with the growth of the older adult population, and it is expected that the 33.9 million cases currently estimated worldwide will triple by $2050 .{ }^{1,2}$ Wandering behavior is one of the most troublesome dementia behavior disturbances and leads to several adverse outcomes such as fractures, getting lost, and untimely death. ${ }^{3-5}$ The number of dementia-related missing persons cases is increasing, with 16,927 cases per year being reported in Japan. ${ }^{6}$ Moreover, wandering behavior is associated with a high care burden for families ${ }^{7}$; they are sometimes sued after accidents that are dementia-related missing persons cases. ${ }^{8}$ There are no efficacious ways to prevent people with dementia from getting lost. ${ }^{9}$ Therefore, there is a need to identify the risk factors for dementia-related missing incidents and the subsequent death and to develop an efficacious way to manage them.

Some studies investigated the characteristics of missing persons cases and their risk factors. One study found that $75 \%$ of older adults with dementia died after going missing due to hypothermia or drowning and that the proportion of older adults living alone who died after a missing event was higher than those found alive. ${ }^{10}$ Another study reported that persons who died after going missing were more likely to get lost at night (from 18:00 to 5:59) and that it took a longer time to submit a missing person's report for persons who died than for persons who were found alive. ${ }^{11}$ Another retrospective observational study found that a higher outdoor landmark density was a significant geospatial factor for missing incidents related to dementia. ${ }^{12}$

There are several studies that investigated the risk factors for missing incidents in persons with dementia and the differences between death cases after dementia-related missing and alive cases after dementia-related missing. However, there is no study that investigates the risk factors for deaths after a dementia-related missing event. Also, few studies have investigated the environmental risk factor for dementia-related missing incidents, such as the care and safety status of older adults. Additionally, there are no data about the incidence rate and mortality rate of dementia-related missing events, despite these being crucial information in determining how often missing events and subsequent deaths occur.

Therefore, the purpose of this study was to describe the incidence rate and mortality rate of dementia-related missing 
Table 1. Detailed summary of variables in this study

\begin{tabular}{|c|c|c|c|c|c|}
\hline Variable name & Unit & Type & Calculation methods & Data source & Year \\
\hline Dementia-related missing event & Case & Outcome & - & $\begin{array}{l}\text { Status of missing from The } \\
\text { National Police Agency }\end{array}$ & 2018 \\
\hline Death after dementia-related missing & Case & Outcome & - & $\begin{array}{l}\text { Status of missing from The } \\
\text { National Police Agency }\end{array}$ & 2018 \\
\hline $\begin{array}{l}\text { The number of nursing care facilities } \\
\text { for older adults per } 100,000 \text { persons } \\
\text { aged } 65 \text { years old or more }\end{array}$ & $\begin{array}{l}\text { Facility per } 100,000 \\
\text { Persons aged } \\
65 \text { years old or more }\end{array}$ & $\begin{array}{l}\text { Explanatory } \\
\text { variables }\end{array}$ & $\begin{array}{l}\text { The number of nursing care } \\
\text { facilities for older adults/the } \\
\text { number of persons aged } \\
65 \text { years old or more }\end{array}$ & $\begin{array}{l}\text { Survey of Institutions and } \\
\text { Establishments for Long-term } \\
\text { Care and Population Census or } \\
\text { estimated population }\end{array}$ & 2017 \\
\hline $\begin{array}{l}\text { The number of policemen per } \\
1,000 \text { persons }\end{array}$ & Person per 1,000 persons & $\begin{array}{l}\text { Explanatory } \\
\text { variables }\end{array}$ & $\begin{array}{l}\text { The number of policemen/total } \\
\text { population }\end{array}$ & $\begin{array}{l}\text { Local government capacity } \\
\text { management survey and } \\
\text { Population Census or estimated } \\
\text { population }\end{array}$ & 2017 \\
\hline $\begin{array}{l}\text { Welfare costs for older adults per } \\
\text { one person aged } 65 \text { years old or more }\end{array}$ & $\begin{array}{l}\text { Thousand yen } \\
\text { per person aged } \\
65 \text { years old or more }\end{array}$ & $\begin{array}{l}\text { Explanatory } \\
\text { variables }\end{array}$ & $\begin{array}{l}\text { Welfare costs for older adults/the } \\
\text { number of persons aged } 65 \text { years } \\
\text { old or more }\end{array}$ & $\begin{array}{l}\text { Local financial status survey and } \\
\text { Population Census or estimated } \\
\text { population }\end{array}$ & 2016 \\
\hline $\begin{array}{l}\text { The number of public health nurses } \\
\text { per } 100,000 \text { persons }\end{array}$ & $\begin{array}{l}\text { Person per } 100,000 \\
\text { persons }\end{array}$ & $\begin{array}{l}\text { Explanatory } \\
\text { variables }\end{array}$ & $\begin{array}{l}\text { The number of public health } \\
\text { nurse/total population }\end{array}$ & $\begin{array}{l}\text { Report on Public Health } \\
\text { Administration and Services and } \\
\text { Population Census or estimated } \\
\text { population }\end{array}$ & 2016 \\
\hline $\begin{array}{l}\text { The number of local welfare officers } \\
\text { per } 100,000 \text { persons }\end{array}$ & $\begin{array}{l}\text { Person per } 100,000 \\
\text { persons }\end{array}$ & $\begin{array}{l}\text { Explanatory } \\
\text { variables }\end{array}$ & $\begin{array}{l}\text { The number of local welfare } \\
\text { officer per } 100,000 \text { persons }\end{array}$ & $\begin{array}{l}\text { Report on Social Welfare } \\
\text { Administration and Services and } \\
\text { Population Census or estimated } \\
\text { population }\end{array}$ & 2016 \\
\hline $\begin{array}{l}\text { Late elderly medical expenses per } \\
\text { one insured person }\end{array}$ & $\begin{array}{l}\text { Thousand yen } \\
\text { per insured person }\end{array}$ & $\begin{array}{l}\text { Explanatory } \\
\text { variables }\end{array}$ & $\begin{array}{l}\text { Late elderly medical expenses/ } \\
\text { insured person }\end{array}$ & $\begin{array}{l}\text { Latter-year medical care business } \\
\text { annual report and Population } \\
\text { Census or estimated population }\end{array}$ & 2016 \\
\hline $\begin{array}{l}\text { The proportion of people who live } \\
\text { in urban areas }\end{array}$ & Percent & $\begin{array}{l}\text { Explanatory } \\
\text { variables }\end{array}$ & $\begin{array}{l}\text { The number of people who live } \\
\text { in urban areas/total population }\end{array}$ & Population Census & 2015 \\
\hline $\begin{array}{l}\text { The proportion of households with } \\
\text { older adults couples only per household }\end{array}$ & Percent & $\begin{array}{l}\text { Explanatory } \\
\text { variables }\end{array}$ & $\begin{array}{l}\text { The number of households with } \\
\text { older adults couples only per } \\
\text { household/total households }\end{array}$ & Population Census & 2015 \\
\hline $\begin{array}{l}\text { The proportion of households with } \\
\text { older adults living alone per household }\end{array}$ & Percent & $\begin{array}{l}\text { Explanatory } \\
\text { variables }\end{array}$ & $\begin{array}{l}\text { The number of households with } \\
\text { older adults living alone per } \\
\text { household/total households }\end{array}$ & Population Census & 2015 \\
\hline Population aged 40 years old or more & Persons & Offset & - & Estimated population & 2018 \\
\hline Proportion of older adults & Percent & $\begin{array}{l}\text { Confounding } \\
\text { variable }\end{array}$ & $\begin{array}{l}\text { The number of persons aged } \\
65 \text { years old or more/total } \\
\text { population }\end{array}$ & Estimated population & 2018 \\
\hline Gross prefectural product & Million yen & $\begin{array}{l}\text { Confounding } \\
\text { variable }\end{array}$ & - & Prefectural Economic Calculation & 2015 \\
\hline
\end{tabular}

-, Not applicable.

events, and to investigate the risk factors for missing incidents and subsequent deaths.

\section{METHODS}

\section{Design and data source}

An exploratory ecological design was used by aggregating data by prefecture; Japan has 47 prefectures. The National Police Agency gave our group the data about dementia-related missing incidents and the subsequent deaths. Other data were extracted from the Japanese government statistics open data (e-stat). ${ }^{13}$ Table 1 shows a detailed explanation of the variables and data source of this study. This study did not require an institutional review board approval, since only aggregate data were used in this study.

\section{Measurements}

Dementia-related missing events and deaths after dementia-related missing

Missing person events and related deaths in 2018 were used as outcomes in present study. ${ }^{6}$ In Japan, there are rules regarding how to find missing persons based on related laws. ${ }^{14}$ This states that a missing person is classified as such when a missing person's report has been submitted by family or other related persons to the police. Missing is defined as having left the living place and the person's location is unknown. Death after submitting a missing person's report is treated as a death after dementia-related missing event. There is the possibility that an individual with dementia gets lost repeatedly and multiple missing persons reports are submitted. If the family or other related persons report that a missing person has dementia, this case is treated as dementia-related missing incident. Only in dementia-related missing events, more detail aggregated data by age $(40-49,50-59,60-69,70-79$, and 80 years or older), sex, and prefectures can be collected.

\section{Total population}

In order to calculate the incidence rate, death rate, and agestandardized incidence rate, we obtained total population data from annual reports which are based on the population Residential Register of Japan. ${ }^{13}$ We extrapolated data from those who were aged 40 years or older, then examined data from 2018 
by age groups $(40-49,50-59,60-69,70-79$, and 80 years or older).

\section{Candidate explanatory variables}

We selected the candidate explanatory variables based on environmental and economic indicators that are expected to be associated with dementia-related missing events and related deaths as the older adults' characteristics, care, and safety. The following variables were selected: the number of nursing care facilities for older adults per 100,000 persons aged 65 years or older, the number of policemen per 1,000 persons, welfare costs for older adults per one person aged 65 years or older, the number of public health nurses per 100,000 persons, the number of local welfare officers per 100,000 persons, late elderly medical expenses per one insured person, the proportion of people who live in the urban area, the proportion of households with only one older adult couple per household, and the proportion of households with older adults living alone per household.

\section{Confounding variables}

We extracted the data of the proportion of older adults and the gross prefectural product. The proportion of older adults and gross prefectural product were used as confounding variables.

\section{Statistical analysis}

The incidence rate and mortality rate of dementia-related missing persons in the Japanese population and each prefecture were calculated by dividing dementia-related missing cases and the cases of death by the total population. Detailed missing incidence information based on age (40-49, 50-59, 60-69, 70-79, and 80 years or older) and sex were extracted in the case of missing events due to dementia. Therefore, the age-standardized incidence rate (direct methods) and age-sex specific incidence rate were calculated only for missing events due to dementia. The agestandardized incidence rate was calculated using the "epitools" package. ${ }^{15}$ Additionally, the generalized linear model (family: quasi-poisson, link: log) was applied to investigate the missing incidences among prefectures, age category, and sex, since there was overdispersion in the missing cases. ${ }^{16}$ The dependent variables were missing event and prefecture, and the age category (40-49, 50-59, 60-69, 70-79, and 80 years or older), sex, and prefecture were entered as the independent variables. The total population of each category was included as an offset variable.

Generalized linear models (family: quasi-poisson, link: log) were also applied to explore correlated factors for dementiarelated missing incidents or subsequent deaths, since there was overdispersion in both. ${ }^{16}$ The total population aged at least 40 years was included as an offset variable. Candidate explanatory variables with $P$-values $<0.05$ were adjusted for the proportion of older adults and gross prefectural product. The incidence rate ratios (IRRs) or the mortality rate ratios with $95 \%$ confidence intervals (CIs) were calculated. As a sensitivity analysis, the same analyses of missing incidents were conducted only in older adults (65 years or older).

Statistical significance was set at $P<0.05$, and all analyses were conducted using $\mathrm{R}$ (version 3.6.1; $\mathrm{R}$ Foundation for Statistical Computing, Vienna, Austria).

\section{RESULTS}

Incidence rate and mortality rate of dementia-related missing and demographic data

The total incidence of dementia-related missing persons cases and the total subsequent deaths in Japan were 16,927 cases and 508 cases, respectively. The incidence rate and mortality rate per 100,000 person-year in Japan was 21.72 and 0.652 , respectively. The prefectural-level range of dementia-related missing cases was from 34 to 2,117. The prefectural-level range of deaths after dementia-related missing incidents was from 1 to 28 . Figure 1 and Figure 2 depict the incidence rate and mortality rate in Japan and in each prefecture.

Table 2 shows dementia-related missing events, subsequent death, total population, and candidate explanatory variables. The mean proportion of older adults was $30.07 \%$ (standard deviation [SD], 2.97\%). The mean proportion of households with older adults living alone was $11.36 \%$ (SD, 1.86\%).

\section{Age- and sex-specific incidence rate of missing persons and age-standardized incidence rate}

The age-sex specific incidence rates (per 100,000 person-years) of 40-49 year old men, 50-59 year old men, 60-69 year old men, 70-79 year old men, men aged $\geq 80$ years, 40-49 year old women, 50-59 year old women, 60-69 year old women, 70-79 year old women, and women aged $\geq 80$ years were $0.07,0.80$, $8.54,49.22,128.03,0.02,0.84,7.44,38.40$, and 53.51, respectively (eFigure 1a). The age-standardized incidence rate ranged from 3.4 to 28.5 (eFigure 1b). eFigure 1c depicts the IRR from the generalized linear model that investigated the difference from the missing incidence by prefecture, age, and sex. Our analysis showed significant differences in prefectures, age, and sex (range of IRRs: 0.32 to 2.62). Older age was associated with a higher incidence rate of dementia-related missing events. Men were more likely to get lost compared to women (IRR 1.74; 95\% CI, 1.66-1.83). eTable 1 shows the sex and age distributions of the total dementia-related missing events. Dementia-related missing events of men and women were 5,065 and 3,792 cases, respectively.

\section{Associated factors for missing incidents in persons with dementia}

Table 3 shows the results of the associated factors in dementiarelated missing incidents. We found that the number of nursing care facilities for older adults, number of public health nurses, and proportion of people who live in the urban area were associated with dementia-related missing incidents. An increase in the number of nursing care facilities for older adults per 100,000 persons aged 65 years or older by one was associated with a $7.9 \%$ (95\% CI, 3.3-12.4\%) decrease in missing incidents. An increase in the number of public health nurse per 100,000 persons by one was associated with a $3.2 \%$ (95\% CI, 1.6-4.9\%) decrease in missing incidents. A ten percent increase in the proportion of people who live in the urban area was associated with a $20.3 \%$ (95\% CI, 8.7-33.2\%) increase in missing incidents. Figure 3a, Figure $3 \mathrm{~b}$, and Figure $3 \mathrm{c}$ depicts scatter plots and an estimated incidence rate from the non-adjusted generalized linear models results of the number of nursing care facilities for older adults, number of public health nurses, and proportion of people who live in the urban area to show the estimated incidence rate with the distribution of each value. eFigure $2 a$, eFigure $2 b$, and eFigure $2 c$ depicts scatter plots with the prefecture and the number of nursing care facilities for older adults, number of public health nurses, and proportion of people who live in the urban area to determine the specific value of each prefecture. For example, the number of nursing care facilities for the elderly, 
(a)

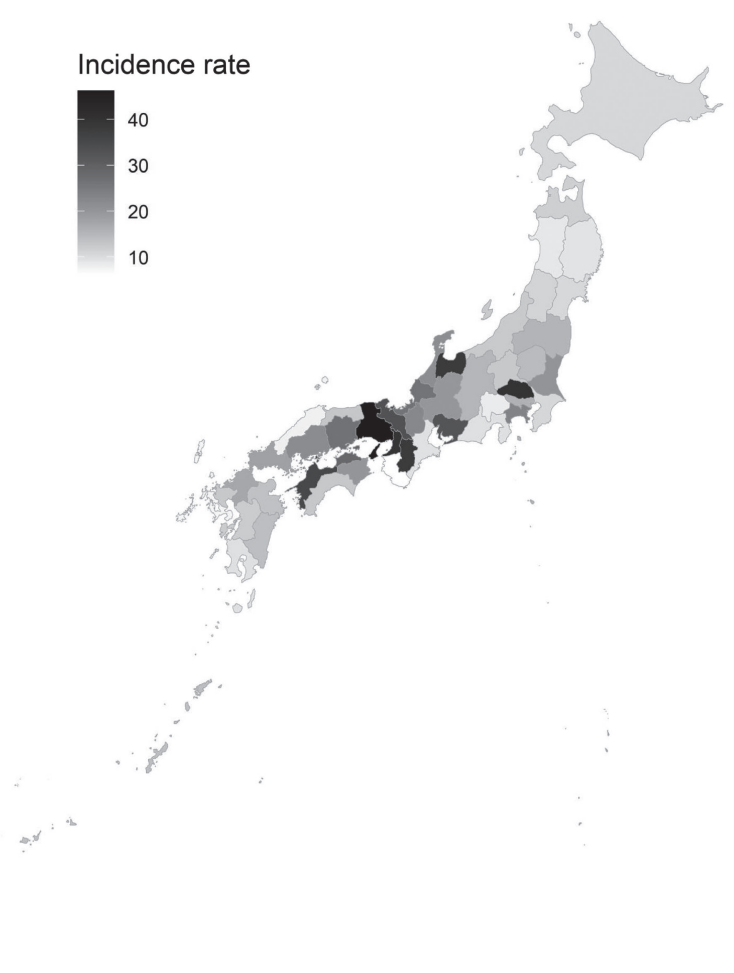

(b)

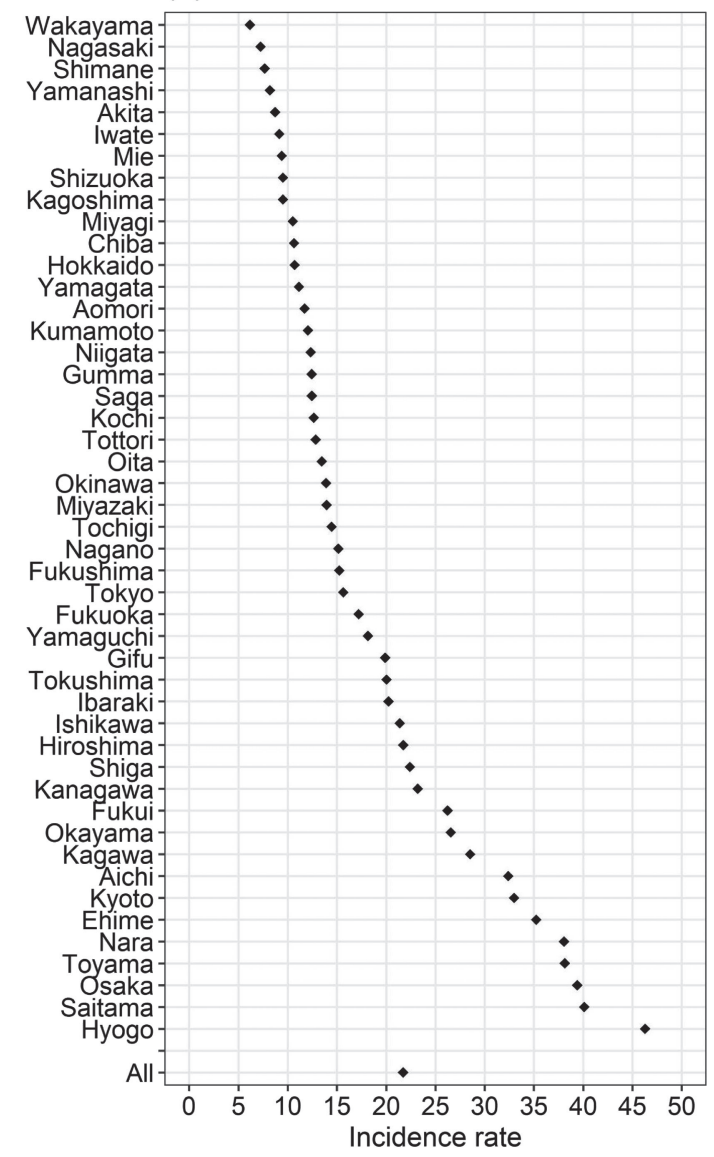

Figure 1. Incidence rate of missing persons with dementia (per 100,000 person-years). Map of Japan showing the incidence rate of missing persons with dementia (per 100,000 person-years) (a), the incidence rate (per 100,000 person-years) in Japan and in each prefecture (b).

number of public health nurses, and proportion of people who live in the urban area were 15.2, 27.6, and 98.4, respectively, in Tokyo, which is the capital of Japan. A sensitivity analysis also showed that a higher number of public health nurses and nursing care facilities, and a lower proportion of people who live in the urban area were associated with a lower incidence rate of dementia-related missing events (eTable 2).

\section{Associated factors for deaths after dementia-related missing person events}

Table 3 also shows the results of the associated factors for deaths after dementia-related missing person events. Our results showed that the proportion of people who live in urban areas was associated with deaths after dementia-related missing events. A ten percent increase in the proportion of people who live in urban areas was associated with a $12.9 \%$ (95\% CI, 5.6-19.8\%) decrease in the mortality rate, even after adjustment for the confounding factors. Figure $3 \mathrm{~d}$ depicts scatter plots and the estimated mortality rate from non-adjusted generalized linear models of the proportion of people who live in urban areas to show the estimated mortality rate with distribution of each value. eFigure $2 d$ also depicts scatter plots with prefectural name of the proportion of people who live in urban areas to determine the specific value of each prefectures. For example, the mortality rates were relatively low in Tokyo, Aichi, and Osaka, which are urban prefectures in Japan.

\section{DISCUSSION}

This is the first study to report the incidence rate and mortality rate of dementia-related missing events. Results indicated that there was a difference in the incidence rate by prefecture. Men were more likely to have missing events compared to women, and older age was associated with higher missing incidence rates. A high number of nursing care facilities for older adults, a high number of public health nurses, and a low proportion of people who live in urban areas were associated with a low rate of missing incidents. A high proportion of people who live in the urban areas was associated with a low mortality rate after missing incidents.

Our study clarified differences in the incidence rate of missing events among prefectures and found that sex (ie, men) and advanced age were associated with more missing events. Previous studies showed no significant difference in age and sex between dementia patients with missing incidence and dementia patients without missing incidence. ${ }^{17}$ Our study had a large sample size and strong statistical power. Our study also clarified that there were large differences in incidence rates among prefectures. Thus, our study provides further insights on characteristics of persons with dementia who get lost and additional findings about differences in prefectures in terms of the incidence rate of missing events.

Our results showed that a high proportion of people who live in urban areas was associated with a high incidence rate of 
(a)

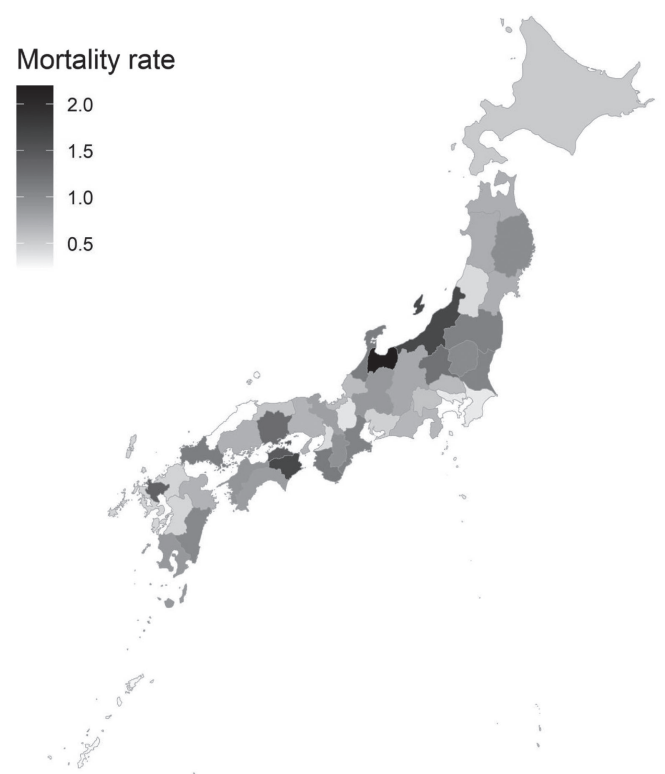

(b)

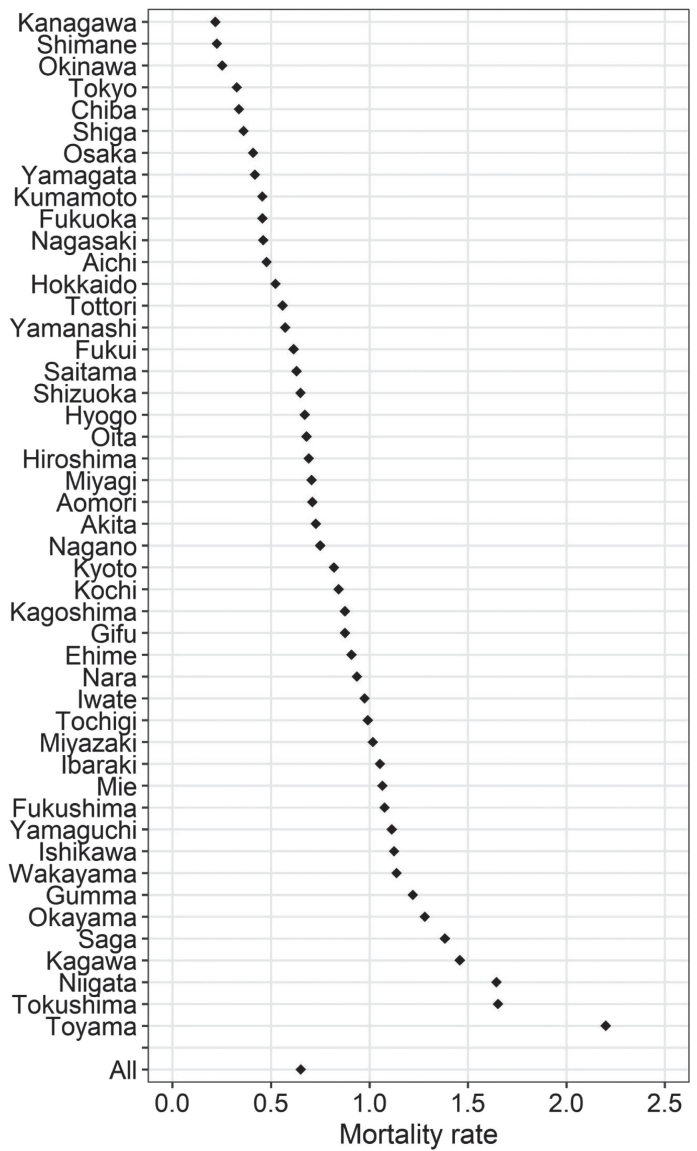

Figure 2. Mortality rate of missing persons with dementia (per 100,000 person-years). Map of Japan showing the mortality rate of missing in persons with dementia (per 100,000 person-years) (a), and the mortality rate (per 100,000 person-years) in Japan and in each prefecture (b).

Table 2. Description of dementia-related missing event, subsequent death, total population, and candidate explanatory variables

\begin{tabular}{|c|c|}
\hline Variable & Overall $(n=47)$ \\
\hline The number of discovered cases after dementia-related missing event & $345.26(488.91)$ \\
\hline Number of dementia-related missing events & $360.15(496.34)$ \\
\hline Number of dementia-related missing events in older adults & $349.94(482.01)$ \\
\hline Incidence rate of dementia-related missing [per 100,000 person-year] & $18.62(10.38)$ \\
\hline The number of deaths after dementia-related missing & $10.81(6.76)$ \\
\hline Mortality rate of dementia-related missing [per 100,000 person-year] & $0.82(0.42)$ \\
\hline Population of older adults & $756,914.89(681,602.10)$ \\
\hline Population of people aged 40 years old or more & $1,658,510.64(1,630,361.63)$ \\
\hline Proportion of older adults [\%] & $30.07(2.97)$ \\
\hline Gross prefectural Product [million yen] & $11,628,733.85(16,58,308.01)$ \\
\hline The number of nursing care facilities for the older adults [building per 100,000 older adults] & $23.25(4.59)$ \\
\hline The number of policemen [person per 1,000 persons] & $1.96(0.30)$ \\
\hline Welfare costs for older adults [thousand yen per older adult aged 65 years old or more] & $207.71(22.76)$ \\
\hline The number of public health nurses [per 100,000 persons] & $49.55(12.68)$ \\
\hline The number of local welfare officers [per 100,000 persons] & $225.90(55.41)$ \\
\hline Late elderly medical expenses [thousand yen per insured] & $930.35(106.56)$ \\
\hline The proportion of people who live in urban areas [\%] & $52.53(18.92)$ \\
\hline The proportion of households with older adults staying as a couples only [\%] & $12.09(1.57)$ \\
\hline The proportion of households with older adults living alone [\%] & $11.36(1.86)$ \\
\hline
\end{tabular}

All data was shown as mean (standard deviation).

dementia-related missing events. A previous retrospective observational study showed that higher outdoor landmark density is a significant geospatial factor for missing incidents in dementia, ${ }^{12}$ and this group suggested it is unclear why this result was found. Outdoor landmarks consist of food shops, churches, parks, hospitals, stations, traffic signals, streetlamps, towers, and so on. One possible explanation of our result may be the same as that of this retrospective observational study, since higher outdoor 
Table 3. Association of the candidate variables with missing incident and death after missing in persons with dementia: generalized linear model

\begin{tabular}{|c|c|c|c|c|c|c|c|c|}
\hline & \multicolumn{4}{|c|}{ Missing incident } & \multicolumn{4}{|c|}{ Death after missing } \\
\hline & \multicolumn{2}{|c|}{ Crude model } & \multicolumn{2}{|c|}{ Adjusted model $^{\mathrm{a}}$} & \multicolumn{2}{|c|}{ Crude model } & \multicolumn{2}{|c|}{ Adjusted model ${ }^{\mathrm{a}}$} \\
\hline & IRR (95\% CI) & $P$ & IRR $(95 \%$ CI) & $P$ & IRR $(95 \%$ CI) & $P$ & IRR $(95 \% \mathrm{CI})$ & $P$ \\
\hline The number of nursing care facilities for older adults & $\begin{array}{c}0.951 \\
(0.921-0.982)\end{array}$ & 0.004 & $\begin{array}{c}0.921 \\
(0.876-0.967)\end{array}$ & 0.002 & $\begin{array}{c}1.071 \\
(1.045-1.097)\end{array}$ & $<0.001$ & $\begin{array}{c}1.033 \\
(0.997-1.071)\end{array}$ & 0.081 \\
\hline The number of policemen & $\begin{array}{c}0.962 \\
(0.674-1.336)\end{array}$ & 0.824 & - & & $\begin{array}{c}0.660 \\
(0.441-0.953)\end{array}$ & 0.040 & $\begin{array}{c}0.976 \\
(0.573-1.628)\end{array}$ & 0.927 \\
\hline Welfare costs for older adults & $\begin{array}{c}0.994 \\
(0.988-1.000)\end{array}$ & 0.055 & - & & $\begin{array}{c}1.004 \\
(0.998-1.011)\end{array}$ & 0.218 & - & \\
\hline The number of public health nurses & $\begin{array}{c}0.980 \\
(0.969-0.990)\end{array}$ & 0.001 & $\begin{array}{c}0.968 \\
(0.951-0.984)\end{array}$ & $<0.001$ & $\begin{array}{c}1.020 \\
(1.011-1.030)\end{array}$ & $<0.001$ & $\begin{array}{c}1.002 \\
(0.989-1.016)\end{array}$ & 0.723 \\
\hline The number of local welfare officers & $\begin{array}{c}0.998 \\
(0.995-1.000)\end{array}$ & 0.091 & - & & $\begin{array}{c}1.005 \\
(1.003-1.007)\end{array}$ & $<0.001$ & $\begin{array}{c}0.999 \\
(0.994-1.005)\end{array}$ & 0.761 \\
\hline Late elderly medical expenses & $\begin{array}{c}1.001 \\
(1.000-1.002)\end{array}$ & 0.140 & - & & $\begin{array}{c}0.999 \\
(0.998-1.001)\end{array}$ & 0.275 & - & \\
\hline The proportion of people who live in urban areas & $\begin{array}{c}1.010 \\
(1.003-1.017)\end{array}$ & 0.005 & $\begin{array}{c}1.019 \\
(1.008-1.029)\end{array}$ & 0.001 & $\begin{array}{c}0.982 \\
(0.978-0.987)\end{array}$ & $<0.001$ & $\begin{array}{c}0.986 \\
(0.978-0.994)\end{array}$ & 0.002 \\
\hline The proportion of households with older adults living as a couples & $\begin{array}{c}1.023 \\
(0.932-1.126)\end{array}$ & 0.642 & - & & $\begin{array}{c}1.172 \\
(1.068-1.289)\end{array}$ & 0.002 & $\begin{array}{c}0.973 \\
(0.869-1.091)\end{array}$ & 0.640 \\
\hline The proportion of households with older adults living alone & $\begin{array}{c}1.006 \\
(0.914-1.104)\end{array}$ & 0.899 & - & & $\begin{array}{c}1.016 \\
(0.919-1.120)\end{array}$ & 0.751 & - & \\
\hline
\end{tabular}

CI, confidence interval; IRR, incidence rate ratio; - , Not applicable.

${ }^{a}$ Adjusted models were applied using explanatory variables which are statistically significant in crude model with proportion of older adults and gross prefectural product as confounding factor.

(a)

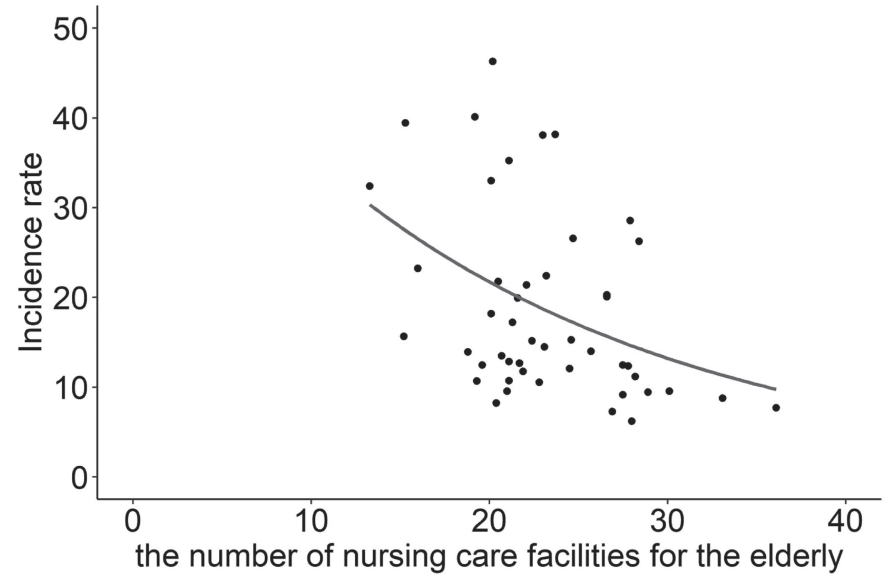

(c)

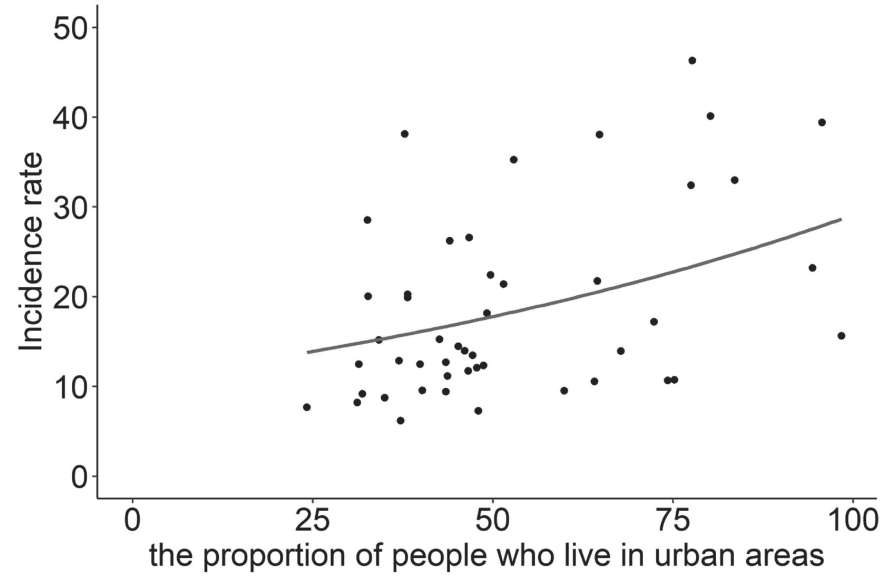

(b)

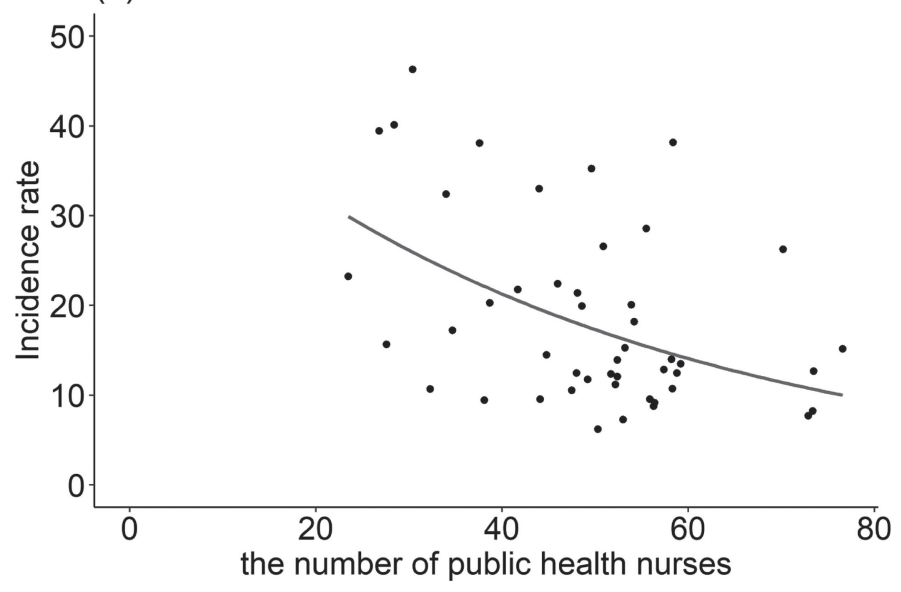

(d)

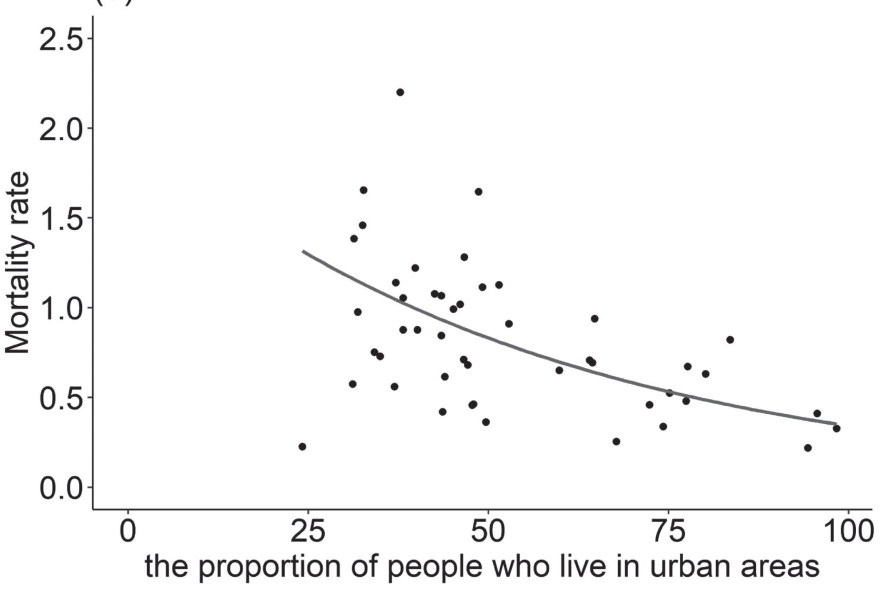

Figure 3. Scatter plot and estimated value from generalized linear model. Points suggest each value and lines suggest estimated value from generalized linear model. (a) is about the incidence rate and the number of nursing care facilities for the elderly, (b) is about the incidence rate and the number of public health nurses, (c) is about the incidence rate and the proportion of people who live in urban areas, and (d) is about the mortality rate and the proportion of people who live in urban areas. 
landmark density is thought to correspond to urban areas. People with dementia living in urban areas can go out easily. On the contrary, people with dementia living in rural areas have difficult to go out for walks, since it is frequently very far from their house to other place. People usually transport using cars or motorcycles for transportation in rural areas. Most people with dementia who get lost and die after going missing had gone out walking. ${ }^{18,19}$ Therefore, the difference in the ease of going out between urban and rural areas may account for the difference in the incidence rate. Additionally, our results showed that the high proportion of people who live in urban areas was associated with the low mortality rate of missing events. The possible explanation of this result might be the difference in other persons' ease of finding the person getting lost. In urban areas, given the high population density, people who get lost are frequently seen by others. On the contrary, people who get lost in rural areas often go unseen. Therefore, our findings are partly in line with those of previous studies, expand on previous studies, and provide further insight.

This is the first study showing associations between a high number of nursing care facilities and public health nurses is associated with a low incidence rate of dementia-related missing persons, which hampers comparisons with other studies. In Japanese nursing care homes, few missing events occurred under enough management of care staff. Thus, the association between the number of nursing care facilities for older adults and incidence rate of dementia-related missing is plausible. Additionally, public health nurses visit most community-dwelling people and provide various interventions to promote healthy life. This association is also possible.

Previous studies showed that the proportion of living alone was higher in older adults with dementia who died after missing events than in older adults with dementia who were alive after missing events. ${ }^{10}$ However, our results could not clarify the association between proportion of older adults living alone and death after dementia-related missing events. There were differences in included participants and study designs among the studies. Our study included people aged 40 years or more, whereas previous studies included persons with dementia who get lost. This difference may lead to different results, and further research should be conducted using a large individual-level cohort study.

Our results have some practical implications. First, public health nurse activity may be efficacious to prevent dementiarelated missing events. Further research should be conducted to clarify the efficacy of this management method using an intervention study. Second, the proportion of people who live in urban areas and the number of nursing care facilities for older adults can help prefectures or cities to predict missing incidence rates and the mortality rate of missing persons. Different strategies should be considered according to prefecture and urban or rural living situation.

Despite the important findings of this study, its limitations should be taken into account. First, the present study design was an ecological study. Therefore, ecological fallacy exists. Further research should be conducted by collecting individual-level data and using case control study that is feasible. However, cases of death after going missing and dementia-related missing cases are rare. Therefore, sampling should be conducted at the countrylevel. Second, we could not assess cases that were not reported to the police despite the occurrence of missing event. These unreported missing cases are possible when the persons live alone, have no close neighbors, and receive no long-term care insurance services. Though these situations may be rare, dementia-related missing event may also be underestimated. Third, our study had no information about cases that were not found long after the person had gone missing. Though most of these cases are expected to be dead, this study did not include those cases. Thus, death after dementia-related missing events may be underestimated. Fourth, our study did not have detailed information about death after missing events grouped by age and sex. Therefore, we could not calculate the age-standardized mortality rate and the age- and sex-specific mortality rate. Finally, this study used different time points between outcome variables and candidate explanatory variables.

In conclusion, our results showed that a high number of nursing care facilities for older adults, a high number of public health nurses, and a low proportion of people living in urban areas were associated with low missing incidence rates, and that a high proportion of people living in urban areas was associated with low death rates after dementia-related missing events. There was much prefectural difference in incidence rate and mortality rate. Men were more likely to have more missing events compared to women, and higher age was associated with higher missing events. Further individual level cohort studies should be conducted to eliminate the ecological fallacy limitation in the present study.

\section{ACKNOWLEDGMENTS}

We thank the National Police Agency's staff, Ms. Niho, for help with data acquisition. This study was supported by research grants from the Osaka Gas Group Welfare Foundation and the Foundation for Total Health Promotion.

Conflicts of interest: None declared.

Author contribution: SM contributed to the conception or design of the work, the acquisition, analysis, and interpretation of data for the work, and wrote the initial draft of the manuscript. MT contributed to the conception or design of the work, the acquisition, analysis, and interpretation of data for the work, and revised it critically for important intellectual content. DO contributed to the conception or design of the work, the acquisition of data for the work, and revised it critically for important intellectual content. $\mathrm{YN}, \mathrm{AH}$, and $\mathrm{KN}$ contributed to the conception or design of the work and revised it critically for important intellectual content. All authors have confirmed the final version of the manuscript.

\section{APPENDIX A. SUPPLEMENTARY DATA}

Supplementary data related to this article can be found at https:// doi.org/10.2188/jea.JE20200113.

\section{REFERENCES}

1. Barnes DE, Yaffe K. The projected effect of risk factor reduction on Alzheimer's disease prevalence. Lancet Neurol. 2011;10(9):819828 .

2. Brookmeyer R, Johnson E, Ziegler-Graham K, Arrighi HM. Forecasting the global burden of Alzheimer's disease. Alzheimers Dement. 2007;3(3):186-191.

3. Buchner DM, Larson EB. Falls and fractures in patients with Alzheimer-type dementia. JAMA. 1987;257(11):1492-1495. https:// www.ncbi.nlm.nih.gov/pubmed/3820464. Published 1987/03/20. 
4. Gurwitz JH, Sanchez-Cross MT, Eckler MA, Matulis J. The epidemiology of adverse and unexpected events in the long-term care setting. J Am Geriatr Soc. 1994;42(1):33-38.

5. Kibayashi K, Shojo H. Accidental fatal hypothermia in elderly people with Alzheimer's disease. Med Sci Law. 2003;43(2):127-131.

6. Statistics on missing persons 2018. [Heisei 30 nen ni okeru yukuefumei-sha no jokyo]. National Police Agency. https://www.npa.go. jp/safetylife/seianki/fumei/H30yukuehumeisha.pdf (in Japanese). Accessed Dec 24, 2019.

7. Rolland Y, Gillette-Guyonnet S, Nourhashémi F, et al. [Wandering and Alzheimer's type disease. descriptive study. REAL.FR research program on Alzheimer's disease and management]. Rev Med Interne. 2003;24(Suppl 3):333s-338s.

8. Young Y, Papenkov M, Nakashima T. Who is responsible? A man with dementia wanders from home, is hit by a train, and dies. $J \mathrm{Am}$ Med Dir Assoc. 2018;19(7):563-567.

9. Emrich-Mills L, Puthusseryppady V, Hornberger M. Effectiveness of interventions for preventing people with dementia exiting or getting lost. Gerontologist. 2019.

10. Kikuchi K, Ijuin M, Awata S, Suzuki T. Exploratory research on outcomes for individuals missing through dementia wandering in Japan. Geriatr Gerontol Int. 2019;19(9):902-906.

11. Saito T, Murata C, Jeong S, Inoue Y, Suzuki T. Prevention of accidental deaths among people with dementia missing in the community in Japan. Geriatr Gerontol Int. 2018;18(8):1301-1302.

12. Puthusseryppady V, Coughlan G, Patel M, Hornberger M. Geospatial analysis of environmental risk factors for missing dementia patients. J Alzheimers Dis. 2019;71(3):1005-1013.

13. Portal Site of Official Statistics of Japan. Ministry of Internal Affairs and Communication. https://www.e-stat.go.jp/en/regional-statistics/ ssdsview/prefectures. Accessed Dec 16, 2019.

14. The rule about finding activity of Missing persons (in Japanese). Ministry of Internal Affairs and Communications. https://elaws. e-gov.go.jp/search/elawsSearch/elaws_search/lsg0500/detail?lawId= 421M60400000013. Accessed Dec 24, 2019.

15. Aragon T, Fay M, Wollschlaeger D. EpiTools: R package for epidemiologic data and graphics. $R$ Package version 05-7. 2012.

16. Agresti A. An introduction to categorical data analysis. Hoboken, NJ: John Wiley \& Sons; 1996.

17. Okita M, Hanyu H, Hirao K, Shimizu S, Umahara T, Sakurai H. Missing incidents in individuals with dementia attending a memory clinic. J Am Geriatr Soc. 2016;64(6):1365-1366.

18. Suzuki T. Study on wandering/missing/deceased of elderly with dementia. Japanese Society of Safety Promotion. 2017;10(1):6-13 (in Japanese).

19. Furumiya J, Hashimoto Y. A descriptive study of elderly patients with dementia who dieda wandering outdoors in Kochi Prefecture, Japan. Am J Alzheimers Dis Other Demen. 2015;30(3):307-312. 